\title{
PERANCANGAN APLIKASI PELAYANAN ONLINE PENCUCIAN KENDARAAN BERBASIS WEBSITE PADA MASTER CLEAN
}

\author{
Tubagus Riko Rivanthio \\ Politeknik LP3I Bandung \\ Email: riko_rivanthio@yahoo.com
}

\begin{abstract}
Abstrak: Penelitian ini memiliki tujuan untuk merancang aplikasi dalam melakukan pelayanan secara online untuk pencucian kendaraan di Master Clean. Tujuan aplikasi ini mengatasi permasalahan banyaknya antrian kendaraan yang akan dicuci mengakibatkan pelanggan mencari tempat cuci yang lain karena tidak ada informasi jumlah dan lama antrian kendaraan yang akan dicuci.. Adapun pelayanan yang tersedia pada online yaitu : Booking Online, informasi antrian kendaraan yang sedang dicuci, informasi biaya dan fasilitas yang dimiliki oleh Master Clean. Metode yang dalam penelitian ini menggunakan teknik Waterfall, yang terdiri dari Requirement Analysis, Design, Development, Testing, Maintenance. Aplikasi pelayanan online pencucian pada Master Clean diharapkan dapat membantu mengatasi permasalahan yang terjadi di Master Clean.
\end{abstract}

Kata Kunci: aplikasi, pelayanan, online, pencucian.

\section{Pendahuluan}

Master Clean merupakan usaha kecil menengah yang bergerak dalam bidang jasa pencucian kendaraan baik kendaraan roda dua maupun roda empat. Setiap harinya Master Clean melayani jasa pencucian kendaraan dimulai dari jam 10.00 WIB sampai dengan 21.00. Pada rentang waktu tersebut Master Clean dapat melayani pencucian mobil sebanyak 25 - 35 mobil dan motor dengan jumlah pegawai 6 orang, terlebih lagi jika di hari sabtu dan minggu pengunjung bisa lebih dari 40 kendaraan. Master Clean memiliki dua tempat cuci mobil yang memiliki hidrolik dan satu tempat cuci motor tanpa hidrolik.

Dalam melakukan pelayanan pencucian mobil, Maser Clean memiliki kendala utama yaitu sering terjadinya antrian kendaraan yang akan dicuci. Dengan banyaknya antrian kendaraan yang akan dicuci mengakibatkan para pelanggan kurang terpuaskan dengan pelayanan sehingga mereka lebih memilih mencari tempat cuci yang lain. Sehingga lambat laun akan pelanggan master clean akan berkurang. Selain memiliki masalah antrian, Master Clean memiliki masalah yang lainnya yaitu, tidak tercatatnya dengan baik jumlah kendaraan, mengakibatkan tidak tahu mana pelanggan tetap dan pelanggan yang tidak tetap, hal ini diperlukan untuk mengetahui tingkat loyalitas pelanggan terhadap master clean dan pemberian reward kepada pelanggan yang memiliki tingkat loyalitas yang tinggi.

Dengan terjadinya masalah-masalah tersebut, maka dibutuhkan suatu solusi untuk memecahkan masalah tersebut. Salah satu solusi tersebut adalah dibutuhkan suatu perangkat yang dapat memberikan informasi jumlah antrian kepada pelanggan, lama waktu tunggu antrian kepada pelanggan, dan perangkat yang dapat mencatat data pelanggan. Maka dari itu perlu dibuatkan aplikasi untuk pelayanan online. Aplikasi yang akan dibuat adalah aplikasi berbasis website, agar semua orang dapat mengakses aplikasi 
tersebut kapan dan dimana saja. Berbeda jika aplikasi berbasis android, dimana jika ingin mengakses harus mengunduh dan menginstal terlebih dahulu.

Perancangan aplikasi ini menggunakan metode waterfall. Menurut Sukamto(2015), model waterfall menggunakan pendekatan alur hidup perangkat lunak secara sekuensial, yaitu dimulai dari analis, desain, pengkodean, dan pengujian. Aplikasi pelayanan online pencucian pada Master Clean diharapkan dapat membantu mengatasi permasalahan yang terjadi di Master Clean.

\subsection{Tujuan Khusus Penelitian}

Tujuan yang ingin dicapai dari penelitian ini adalah merancang aplikasi pelayanan pencucian online berbasis website pada pencucian kendaraan Master Clean. Sedangkan tujuan khusus dari penelitian ini adalah :

1. Mengatasi permasalahan banyaknya antrian kendaraan yang akan dicuci.

2. Diperolehnya perangkat yang dapat mencatat jumlah dan data pelanggan yang melakukan pencucian di Master Clean

\subsection{Rumusan Masalah}

Berdasarkan latarbelakang bahwa penelitian ini memiliki tujuan untuk memperoleh pola atau model dalam pemilihan jurusan pada siswa SMA PGRI 1 Subang, maka dari itu untuk mencapai tujuan tersebut diperlukan rumusan masalah yang terdiri dari :

1. Bagaimanakah memberikan informasi jumlah antrian kendaraan kepada calon pelanggan yang akan dicuci kendaraannya?.

2. Bagaimanakah merancang aplikasi pelayanan pencucian online berbasis website pada pencucian kendaraan Master Clean.

\section{Tinjauan Pustaka}

\subsection{Pengertian Perancangan Aplikasi}

Menurut Presman dalam Syukroni (2017), Perancangan merupakan dasar utama dalam membuat aplikasi, dengan tujuan memberikan gambaran lengkap dengan jelas kepada programmer tentang aplikasi yang akan dibuat. perancangan atau rancang merupakan serangkaian prosedur untuk menterjemahkan hasil analisa dan sebuah sistem ke dalam bahasa pemrograman untuk mendeskripsikan dengan detail bagaimana komponen-komponen sistem diimplementasikan.

Definisi lainnya adalah menurut Sujatmiko (2012:259) "Application merupakan program komputer yang dibuat oleh suatu perusahaan komputer untuk membantu manusia dalam mengerjakan tugas-tugas tertentu".Dari kedua pengertian tersebut, dapat disimpulkan bahwa pengertianAplikasi adalahprogram komputer yangdidesain oleh suatu perusahaan komputer untuk di pakai oleh userdalam mengerjakan tugas-tugas tertentu. 


\subsection{Pengertian Online}

Menurut John M. Echols dan Hasan Shadily yang dipaparkan Erlina Setiyorini memberikan definisi mengenai online. On berarti sedang berlangsung, dan line berarti garis, barisan, jarak dan tema Singkatnya, online berarti proses pengaksesan informasi yang sedang berlangsung melalui media internet.

\section{3. Pengertian Website}

Menurut Bekti (2015:35), "Website merupakan kumpulan halaman-halaman yang digunakan untuk menampilkan informasi teks, gambar diam atau gerak, animasi, suara, dan atau gabungan dari semuanya, baik yang bersifat statis maupun dinamis yang membentuk satu rangkaian bangunan yang saling terkait, yang masing-masing masing dihubungkan dengan jaringan-jaringan halaman".

\subsection{Pengertian Pelayanan}

Pelayanan adalah kegiatan yang dilakukan oleh seseorang atau sekelompok orang dengan landasan faktor materi melalui sistem, prosedur dan metode tertentu dalam rangka usaha memenuhi kepentingan orang lain sesuai dengan haknya. Pelayanan hakikatnya adalah serangkaian kegiatan, karena itu pelayanan merupakan sebuah proses. Sebagai proses, pelayanan berlangsung secara rutin dan berkesinambungan, meliputi seluruh kehidupan orang dalam masyarakat. Moenir (2010 : 26).

\subsection{Pengertian Waterfall}

Menurut Sukamto dan Shalahuddin (2015:28), "Model air terjun menyediakan pendekatan alur hidup perangkat lunak secara sekuensial atau terurut dimulai dari analisis, desain, pengodean, pengujian dan tahap pendukung (support)".

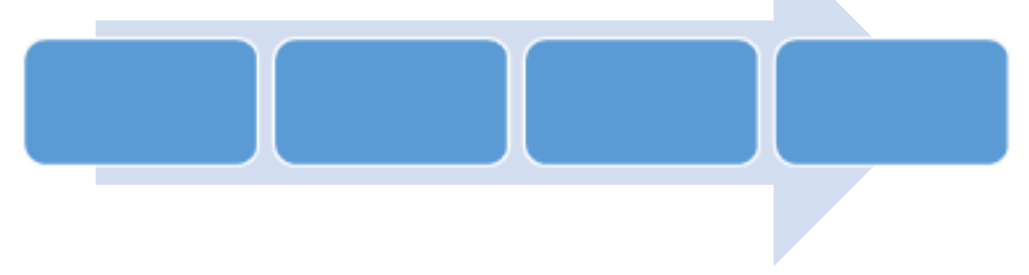

Gambar 1. Model Waterfall

\section{Langkah-langkah Penelitian}

Pada penelitian ini digunakan metode waterfall yang terdiri dari :

a. Analisis

Pada tahap analisis adalah tahap untuk mengidentifikasi kebutuhan yang diperlukan sesuai dengan masalah yang terjadi pada pelayan pencucian Master Clean, yaitu :

1) Modul 
a) Booking online

Modul untuk melakukan booking secara online, agar pelanggan tidak perlu antri dalam melakukan pencucian. Modul ini adalah modul untuk interaksi antara calon pelanggan atau user dengan admin. Sehingga pada user akan tampil form pendaftaran online, sedangkan untuk admin melihat data dan merekap user yang melakukan booking online.

b) Informasi data antrian

Modul untuk melihat jumlah dan estimasi lama antrian sebagi informasi untuk calon pelanggan sebelum melakukan booking secara online maupun offline.

Modul ini terdapat dua tampilan, yang terdiri dari tampilan untuk user adalah data jumlah dan estimasi lama antrian, sedangkan untuk admin adalah tampilan form input data kendaraan yang sedang dicuci dan akan dicuci.

c) Informasi fasilitas dan biaya

Modul untuk melihat fasilitas yang dimiliki dan daftar biaya pelayanan yang terdapat pada pencucian kendaraan di Master Clean.

d) Modul laporan

Modul untuk melihat laporan data pelanggan, jumlah kendaraan yang dicuci dalam periode tertentu berikut jumlah pendapatan yang masuk pada periode tertentu.

2) User

a) Admin

Admin sebagai pengelola website pelayanan online pencucian kendaraan dan dapat mengakses semua modul.

b) Pemilik

Pemilik hanya dapat melihat modul laporan.

c) User

Modul yang bisa diakses : booking online, informasi data antrian, informasi fasilitas dan harga.

3) Media

a) Website online

b) Hosting dan domain

b. Desain

Pada desain perancangan sistem digunakan model UML yang terdiri dari :

1) Activity Diagram

Activity Diagram digunakan untuk menggambarkan aktivitas yang terjadi pada proses pencucian dimaster clean, adapun activity diagramanya adalah sebagai berikut :

1) Transaksi data pencucian 


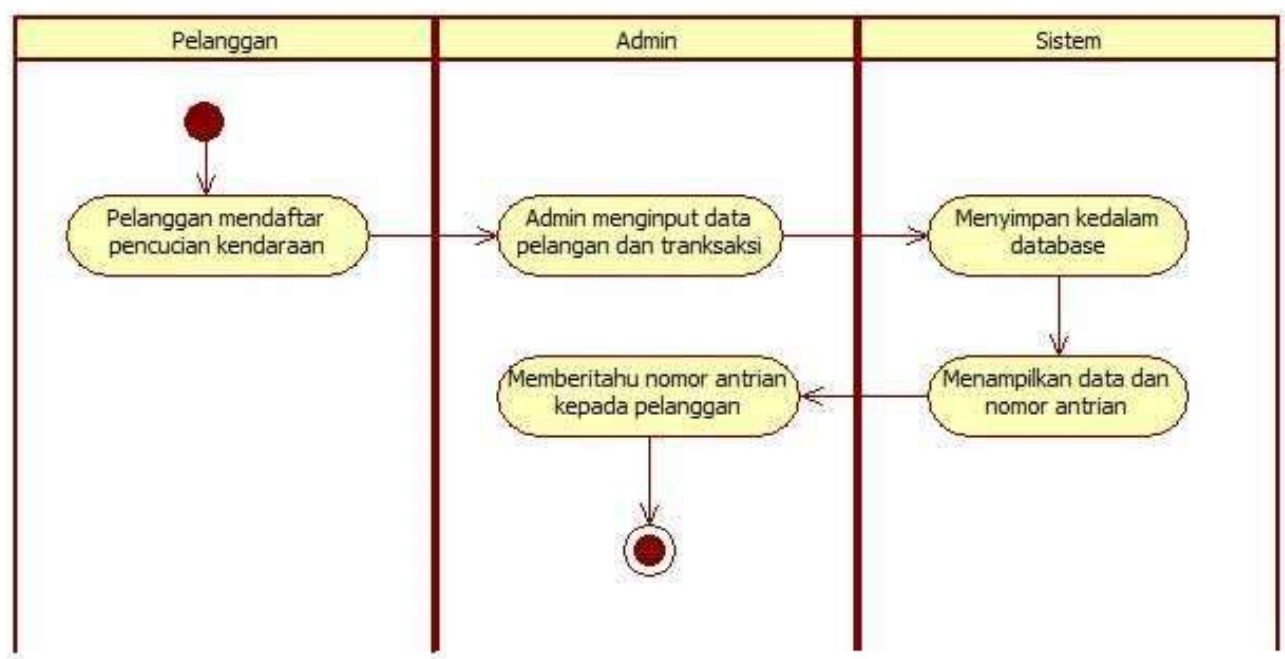

Gambar.1 Aktivitas Transaksi data pencucian

2) Booking Online

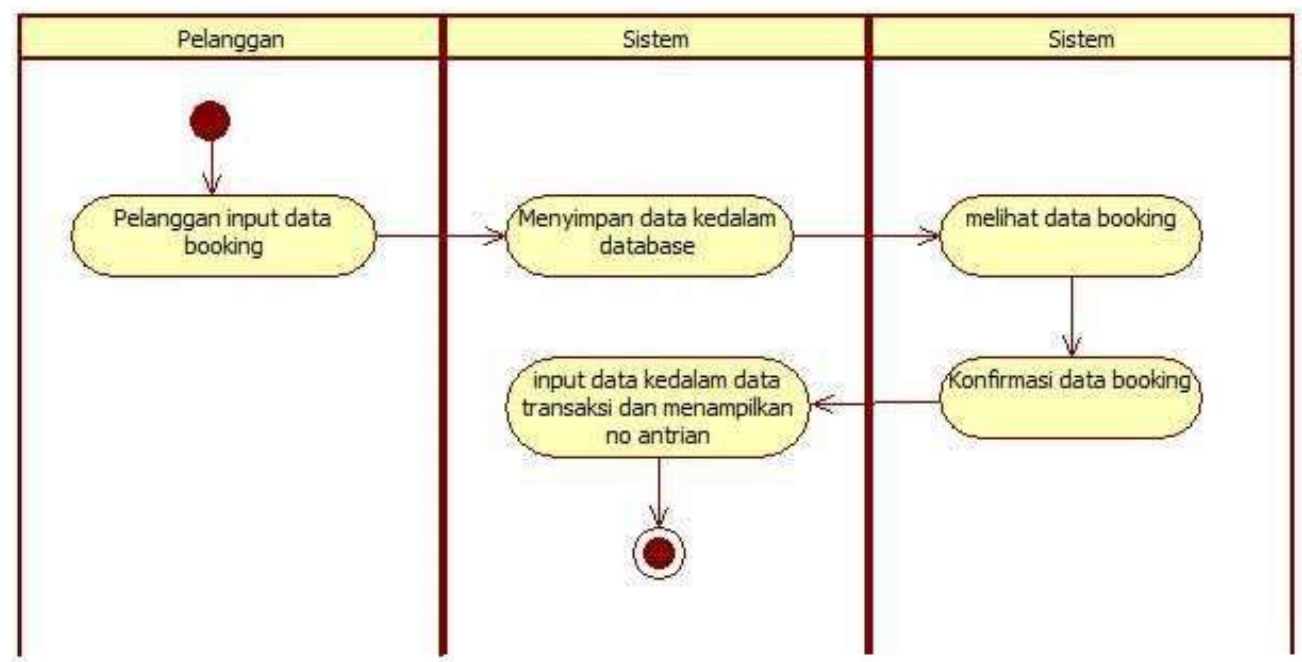

Gambar.2 Aktivitas Booking Online

2) Use Case Diagram

Use Case Diagram digunakan untuk menggambarkan interaksi antara sistem atau aplikasi yang akan dibuat dengan user yang menggakses aplikasi tersebut. 


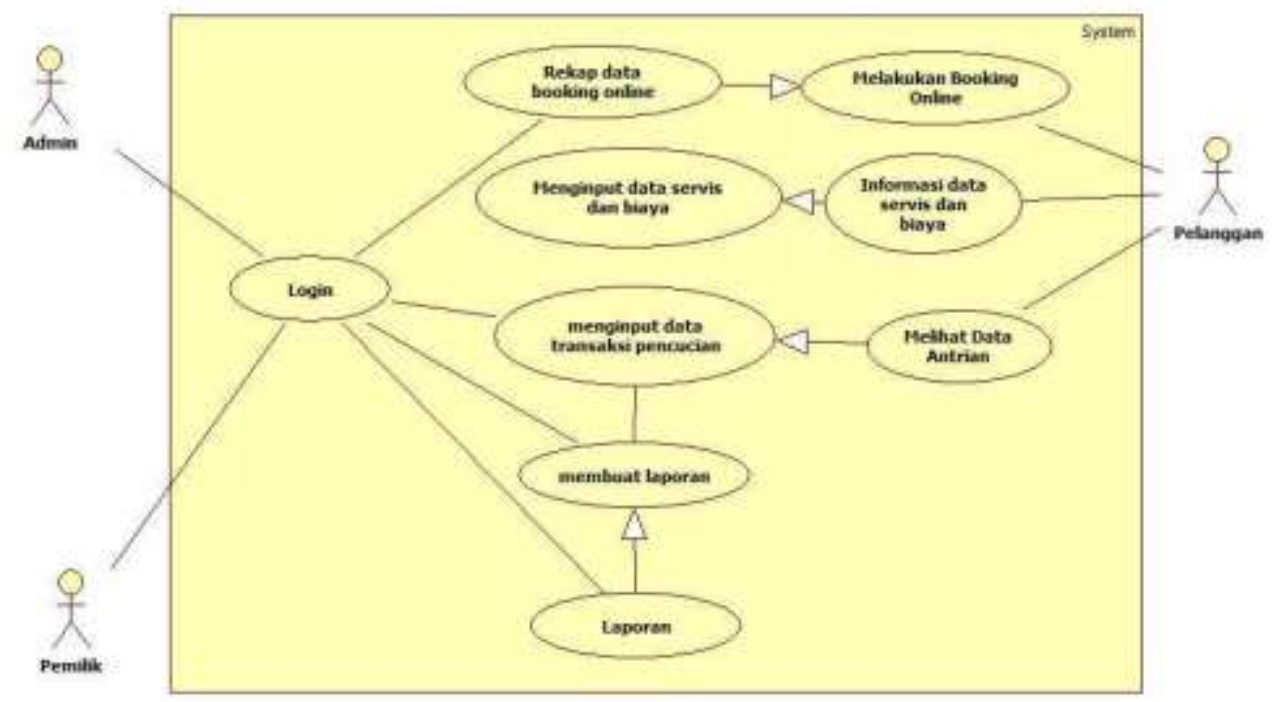

Gambar 3. Use Case Diagram Aplikasi Pelayan Online Pencucian Master Clean

3) Use Case Scenario

Use Case Scenario adalah tabel untuk menggambarkan secara detail proses pada setiap use case yang telah dibuat.

Nama Use Case : Login

Aktor : Admin, Pelanggan

\begin{tabular}{|l|l|}
\hline \multicolumn{1}{|c|}{ Aksi Aktor } & \multicolumn{1}{|c|}{ Reaksi Sistem } \\
\hline $\begin{array}{l}\text { 1. Memasukkan usermane dan } \\
\text { password }\end{array}$ & $\begin{array}{l}\text { 2. Validasi username dan } \\
\text { password }\end{array}$ \\
& $\begin{array}{l}\text { 3. Menampilkan halaman utama } \\
\text { jika username dan password } \\
\text { benar }\end{array}$ \\
\hline
\end{tabular}

Nama Use Case : Melakukan Booking Online

Aktor : Pelanggan

\begin{tabular}{|l|l|}
\hline \multicolumn{1}{|c|}{ Aksi Aktor } & \multicolumn{1}{|c|}{ Reaksi Sistem } \\
\hline 1. Klik menu Booking Online & $\begin{array}{l}\text { 2. Menampilkan form Booking } \\
\text { Online. }\end{array}$ \\
\hline $\begin{array}{l}\text { 3. Menginput data kendaraan dan } \\
\text { data pelanggan }\end{array}$ & $\begin{array}{l}\text { 4. Memasukkan data kedalam } \\
\text { database } \\
\text { 5. Menampilkan konfirmasi } \\
\text { berhasil memasukkan data } \\
\end{array}$ \\
& $\begin{array}{l}\text { 6. Menampilkan data booking } \\
\text { online dan jumlah antrian }\end{array}$ \\
\hline
\end{tabular}


Nama Use Case : Rekap Booking Online

Aktor : Admin

\begin{tabular}{|l|l|}
\hline \multicolumn{1}{|c|}{ Aksi Aktor } & \multicolumn{1}{c|}{ Reaksi Sistem } \\
\hline 1. Klik menu Booking Online & $\begin{array}{l}\text { 2. Menampilkan data Booking } \\
\text { Online. }\end{array}$ \\
\hline $\begin{array}{l}\text { 3. Mengkonfirmasi data booking } \\
\text { Online }\end{array}$ & $\begin{array}{l}\text { 4. Memasukkan data konfirmasi } \\
\text { ke dalam database } \\
\text { 5. Menampilkan data booking } \\
\text { online yang dikonfirmasi }\end{array}$ \\
& $\begin{array}{l}\text { 6. Menampilkan data booking } \\
\text { online dan jumlah antrian }\end{array}$ \\
\hline
\end{tabular}

Nama Use Case : Menginput data Servis dan biaya Aktor : Admin

\begin{tabular}{|l|l|}
\hline \multicolumn{1}{|c|}{ Aksi Aktor } & \multicolumn{1}{|c|}{ Reaksi Sistem } \\
\hline $\begin{array}{l}\text { 1. Klik Menu Input data servis } \\
\text { dan biaya }\end{array}$ & $\begin{array}{l}\text { 2. Menampilkan data form data } \\
\text { servis dan biaya. }\end{array}$ \\
& $\begin{array}{l}\text { 3. Memasukkan data kedalam } \\
\text { database }\end{array}$ \\
& $\begin{array}{l}\text { 4. Menampilkan konfirmasi data } \\
\text { berhasil diinput }\end{array}$ \\
& $\begin{array}{l}\text { 5. Menampilkan data servis dan } \\
\text { biaya }\end{array}$ \\
\hline
\end{tabular}

Nama Use Case : Menginput data transaksi pencucian Aktor : Admin

\begin{tabular}{|l|l|}
\hline \multicolumn{1}{|c|}{ Aksi Aktor } & \multicolumn{1}{c|}{ Reaksi Sistem } \\
\hline 1. Klik menu Transaksi & 2. Menampilkan form transaksi \\
& 3. Memasukkan data kedalam \\
& database \\
& 4. Menampilkan konfirmasi data \\
& berhasil diinput \\
& 5. Menampilkan data transaksi \\
\hline
\end{tabular}

Nama Use Case : Membuat laporan

Aktor : Admin

\begin{tabular}{|l|l|}
\hline \multicolumn{1}{|c|}{ Aksi Aktor } & \multicolumn{1}{c|}{ Reaksi Sistem } \\
\hline 1. Klik menu Laporan & $\begin{array}{l}\text { 2. Menampilkan form laporan } \\
\text { dengan pilihan laporan perhari, } \\
\end{array}$ \\
& perminggu, perbulan \\
& 3. Meampilkan data sesuai pilihan \\
\hline 4. Klik Tombol cetak Laporan & 5. Mencetak laporan \\
\hline
\end{tabular}

Nama Use Case : Melihat laporan 
Aktor : Pemilik

\begin{tabular}{|c|l|}
\hline Aksi Aktor & \multicolumn{1}{|c|}{ Reaksi Sistem } \\
\hline 1. Klik menu Laporan & $\begin{array}{l}\text { 2. Menampilkan form laporan } \\
\text { dengan pilihan laporan perhari, } \\
\text { perminggu, perbulan }\end{array}$ \\
& $\begin{array}{l}\text { 3. Menampilkan data sesuai } \\
\text { pilihan }\end{array}$ \\
\hline
\end{tabular}

4) Class Diagram

\begin{tabular}{|c|c|c|c|}
\hline Data_Pelanggan & Data_transaksi & Data servis & \\
\hline \multirow{3}{*}{$\begin{array}{l}\text { + kode_pelanggan } \\
\text { +nama_pelanggan } \\
\text { +alamat } \\
\text { +no_kendaraan } \\
\text { +jenis_kendaraan }\end{array}$} & \multirow{2}{*}{$\begin{array}{l}\text { +kode_transaksi } \\
\text { +kode_pelanggan } \\
\text { +tanggal } \\
\text { +kode_servis }\end{array}$} & \multirow{2}{*}{$\begin{array}{l}\text { +kode_servis } \\
\text { thama_servis } \\
\text { tbiaya }\end{array}$} & \multirow{3}{*}{$\begin{array}{l}\text { data_booking } \\
\text { +kode_booking } \\
\text { +no_kendaraan } \\
\text { +tanggal } \\
\text { +kode_servis }\end{array}$} \\
\hline & & & \\
\hline & \multirow{2}{*}{$\begin{array}{l}\text { +input0 } \\
\text { +edit0 } \\
\text { thapus0 } \\
\text { +tampil0 }\end{array}$} & \multirow{2}{*}{$\begin{array}{l}\text { +input0 } \\
\text { +edit0 } \\
\text { +hapus0 } \\
\text { +tampil0 }\end{array}$} & \\
\hline $\begin{array}{l}\text { +input0 } \\
\text { +edit0 } \\
\text { thapus0 } \\
\text { +tampil0 }\end{array}$ & & & tinput0 \\
\hline
\end{tabular}

Gambar 4. Class Diagram aplikasi pelayanan online pencucian

c. Pengkodean

Langkah selanjutnya adalah melakukan pengkodean untuk pembuatan web, adapun tools yang digunakan dalam pembuatan website pelayanan online pada Master Clean adalah sebagai berikut :

1) Database : Mysql

2) Kode Fungsi : PHP

3) Kode Tampilan : HTML, CSS Bootstrap

4) Kode Even : Javacript

Sedangkan hasil tampilan adalah sebagai berikut :

a. Halaman Utama

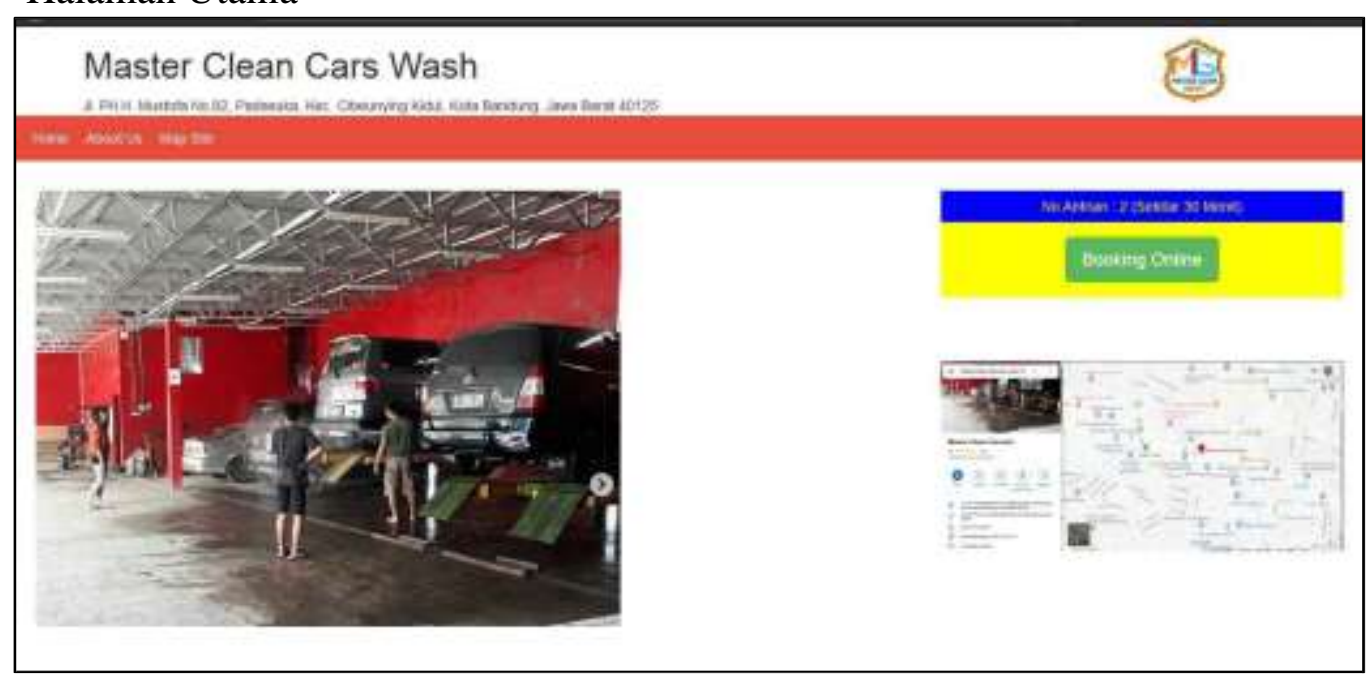


b. Halaman Booking Online

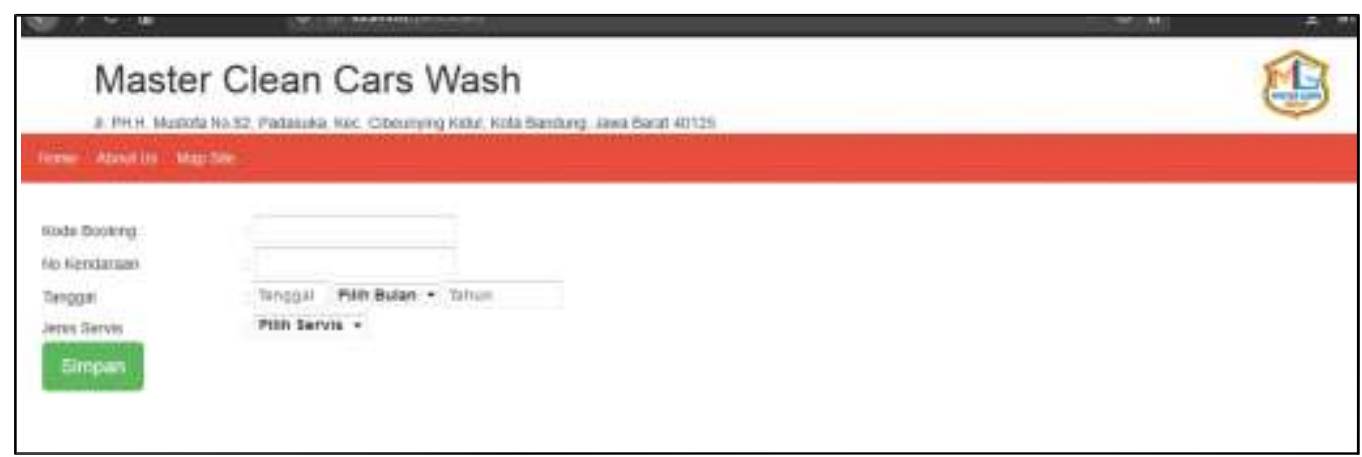

c. Halaman Transaksi

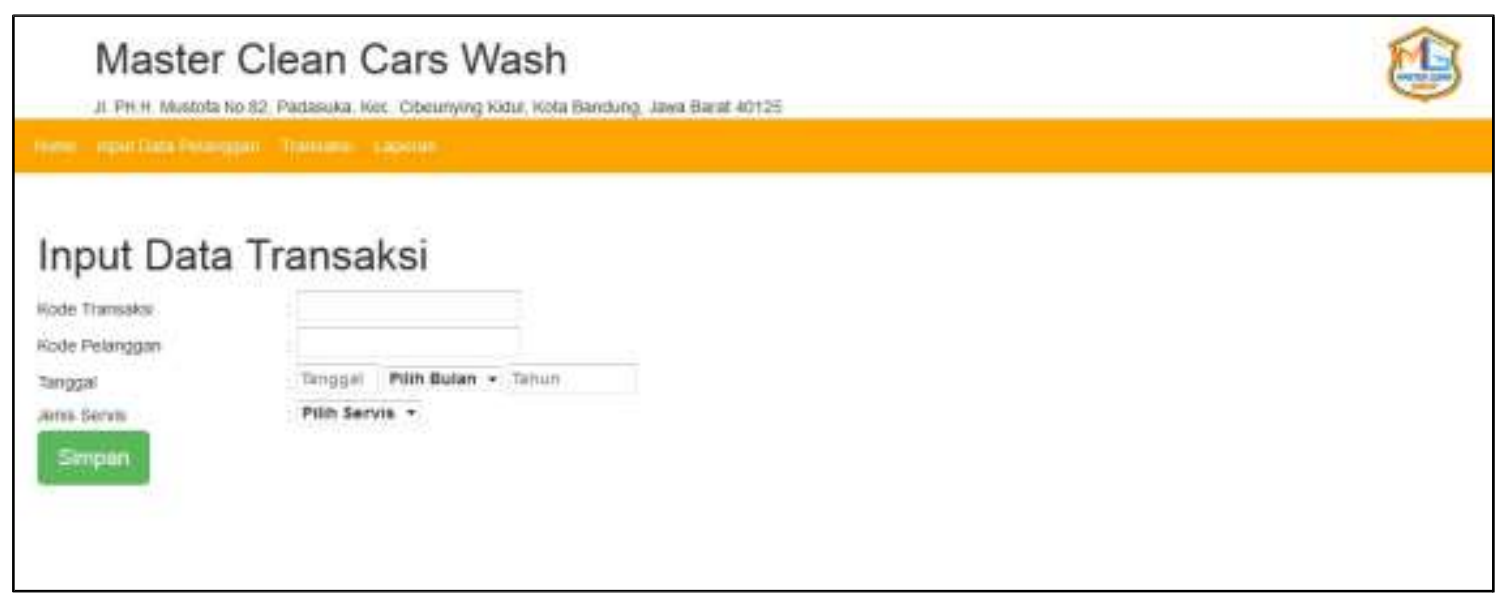

d. Pengujian

Pengujian Aplikasi menggunakan pengujian blackbox

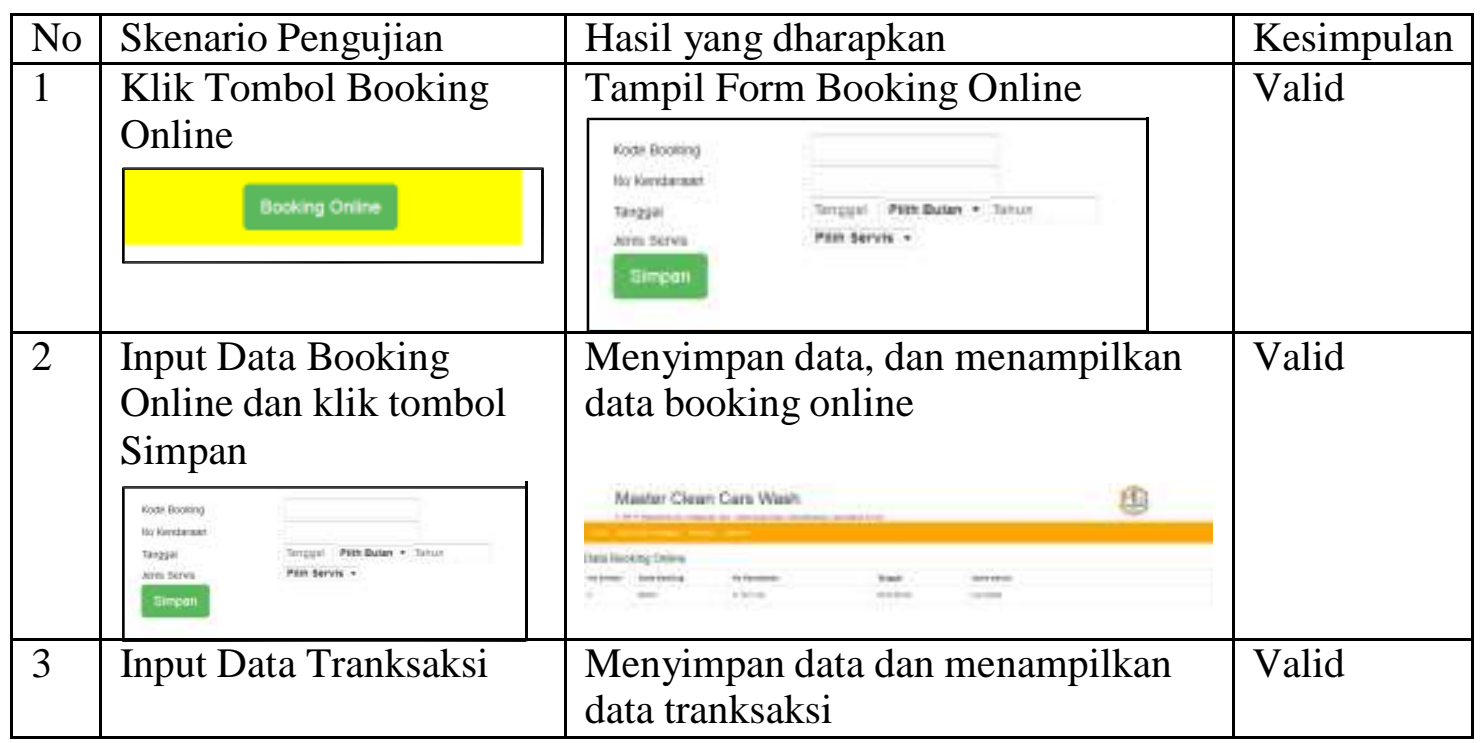




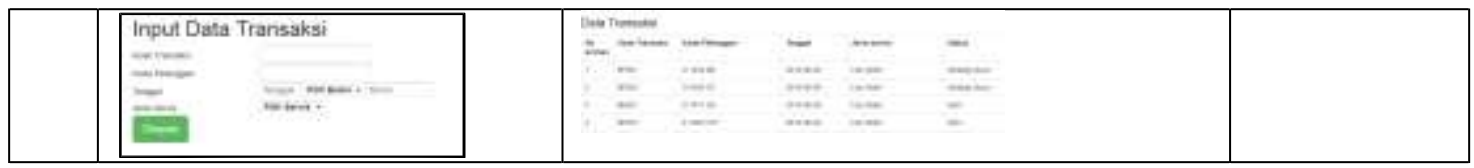

\section{Kesimpulan}

Adapun kesimpulan pada penelitian ini adalah sebagai berikut :

a. Aplikasi Pelayanan Online Berbasis Website ini dapat memberikan informasi data antrian kendaraan yang sedang dicuci di master clean, yatitu dengan adanya informasi data jumlah antrian dan estimasi waktu antri bagi calon kendaraan yang akan dicuci.

b. Aplikasi Pelayanan Online Berbasis Website ini juga dapat digunakan untuk merekap data kendaraan yang dicuci di Master Clean dengan periode yang berbeda yaitu perhari, perminggu, perbulan dan pertahun. Sehingga manajemen Master Clean dapat menentukan strategi dalam memuaskan pelanggan agar tetap loyal terhadap Master Clean.

\section{Daftar Pustaka}

[1] A.S. Moenir, 2010. Manajemen Pelayanan Umum Di Indonesia.Bumi Aksara : Jakarta.

[2] Erlina Setiyorini, Setiyorini (2017) Web media dakwah: studi deskriptife situs resmi PCNU Kota Surabaya. Undergraduate thesis, UIN Sunan Ampel Surabaya.

[3] Bekti, Humaira. 2015. Dreamweaver CS6, CSS dan Jquery. Yogyakarta: ANDI OFFSET

[4] Sujatmiko, Eko. 2012. Kamus Teknologi Informasi dan Komunikasi. Surakarta: AKSARRA SINERGI MEDIA

[5] Syukroni, Muh Farhan (2017) Rancang Bangun Knowledge Management System Berbasis Web Pada Madrasah Mualimin Al-Islamiyah Uteran Geger Madiun. Skripsi thesis, Universitas Muhammadiyah Ponorogo. 